\title{
Sex During Menstruation: Race, Sexual Identity, and Women's Accounts of Pleasure and Disgust
}

\author{
Breanne Fahs
}

In tandem with cultural taboos about menstruation, women have historically reported ambivalent relationships between their body images, sexualities and their menstrual cycles. ${ }^{1}$ From the historic menstrual hut to the recent invention of Premenstrual Dysphoric Disorder (PMDD) to the pervasive social norm encouraging women to hide menstruation from others (Delaney et al., 1988), menstruation has been labeled disgusting, socially deviant and, at times, pathological. Similarly, contemporary women often feel shameful about their bodies in the context of sex, citing body image problems, sexual 'dysfunction', and concerns about feeling normal as key sexual problems (Kleinplatz, 2001; Nobre and Pinto-Gouveia, 2008; Plante, 2006; Tiefer, 2001). Women routinely engage in a variety of normative body practices to manage their 'disgusting' bodies (Roberts and Goldenberg, 2007): hiding menstruation, shaving (Tiggemann and Lewis, 2004), wearing makeup, controlling weight, concealing body odors and grooming extensively.

While some research has addressed women's feelings, emotions and reactions to menstruation - particularly negativity toward menstruation - surprisingly little research has explored how these cultural interpretations of menstruation have influenced women's sexual lives. This study extends existing research by qualitatively examining women's experiences and perceptions of menstruating while having sex (either with male or female partners). Why are women's 
responses polarized, with some embracing menstrual sex and others rejecting it? How might such attitudes relate to partner choice, body image and social identities such as race and sexual identity? This study draws upon qualitative accounts of menstrual sex to add to the growing literature about sexuality, bodies and menstruation by highlighting narratives of pleasure and disgust.

The context within which women menstruate affects not only the discourse surrounding menstruation but also how women themselves experience menstruation (Mansfield and Stubbs, 2007). Historically, menstruation was considered taboo and in need of management (Delaney et al., 1988), as menstrual blood indicated disease, social taboos about decency and shame, and spiritual corruption (Read, 2008). Recent constructions of menstruation in the west carry these same negative cultural connotations (Delaney et al., 1988). Common western cultural constructions treat menstruation as failed reproduction (Kerkham, 2003), particularly because the state constructs women's bodies as reproduction machines (Martin, 2001). Yet, even though negativity permeates cultural and patriarchal attitudes toward menstruation, some cultures (e.g. some African tribes) celebrate it or even attempt to simulate it as a powerful, revered practice (Brain, 1988).

Contemporary western women are barraged with portrayals of menstruation that warn of its so-called disgusting, disabling and tainting qualities. When selling menstrual products, advertisers portray the female body as unclean and unfeminine to market panty liners, pads, and tampons (Berg and Coutts, 1994; Kissling, 2006). Oral contraceptives (e.g. Seasonale) feature menstrual suppression as an asset of taking birth control pills (Johnston-Robledo et al., 2006), thereby amplifying women's interest in suppressing menstruation (JohnstonRobledo et al., 2003; Rose et al., 2008). The invention of premenstrual syndrome (PMS) and PMDD - and their accompanying drug therapies - also promote menstruation as a pharmaceutically managed illness (Endicott et al., 1999). Such portrayals depict women's bodies as debilitated by their monthly cycles, while men's bodies remain 'normal' (Chrisler et al., 2006; Cosgrove and Caplan, 2004; Nicolson, 1995; Offman and Kleinplatz, 2004). Films regularly portray menstruation as revolting (e.g. Superbad (Mottola, 2007)), using menstruation to depict horror and disgust (Briefel, 2005; Kissling, 2002). These portrayals construct women's bodies as dirty, disgusting, and in need of sanitizing, deodorizing, medicating, managing, exfoliating and denuding (Kissling, 2006).

Feminists and other activists have responded to negative portrayals of menstruation by promoting - often through media campaigns, consciousness-raising, educational campaigns and attacks on mainstream representations of menstruation - affirming views of menstruation within institutions such as education, the health industry, media and families (Kissling, 2006). Menstrual activists advocate that women and men cultivate a critical consciousness about menstruation that facilitates positive views of women and their bodies (Bobel, 2008) and have specifically focused their efforts on stopping PMDD from entering the Diagnostic and Statistical Manual of 
Mental Disorders (DSM) (Offman and Kleinplatz, 2004), de-medicalizing menstruation as 'disease' (Koekse, 1983), challenging the toxicity and dangers of commercial menstrual products (Bobel, 2006), embracing menstruation as power and political protest (Aretxaga, 1995), critically examining menstrual suppression products (Johnston-Robledo et al., 2006), and embracing more positive, self-loving messages about women's bodies and menstrual cycles (Kissling, 2006; Stubbs and Costos, 2004). Some argue that cultivating positive attitudes about menstruation unites women, particularly mothers and daughters (Stubbs and Costos, 2004), and may lead to better acceptance of 'imperfect' bodies (Roberts and Waters, 2004).

Despite these efforts, educational settings overwhelmingly promote negative messages about menstruation, as girls learn to associate menstruation with fear, embarrassment, disgust and revulsion (Erchull et al., 2002; Havens and Swenson, 1989). Alarmingly, a recent analysis of menstrual education pamphlets between 1932 and 1997 revealed little differences over time, as all pamphlets promoted secrecy about menstruation (Erchull et al., 2002). Girls in school settings have expressed a strong desire to hide menstruation from others, believing menstruation is an illness rather than a natural occurrence (Burrows and Johnson, 2005) - a phenomenon that persists up through menopause (McKinley et al., 2008).

Given this onslaught of negative messages, imagery and socialization about menstruation, women and girls describe negative attitudes toward menstruation and their bodies. For instance, while nearly 43 percent of girls disliked their bodies in one study, they especially disliked their menstruating bodies (Rembeck et al., 2006). Adult women associated menstruation with uneasiness, pain and maturity (Amann-Gainotti, 1994). Negative attitudes about menstruation persist throughout the lifespan, though some are buffered more against such negativity. Younger girls (Rembeck et al., 2006), those who self-objectify less often (Roberts and Waters, 2004), those with less body shame, with more sexual experience (Schooler et al., 2005), who described breastfeeding as positive (Johnston- Robledo et al., 2007), who have experienced less name-calling from others and who communicated with their mothers about menstruation (Rembeck et al., 2006) described less disgust toward menstruation than others.

Although US culture socializes women to feel negatively toward menstruation, some variation occurs in who embraces such notions. Only one study has examined differences between lesbian and heterosexual women's menstrual attitudes, finding no differences between heterosexual and lesbian-identified women in Mexico (Zepeda and Eugenia, 1999). That said, lesbian women often suffer from internalized homophobia that manifests itself as body shame and dissatisfaction (Pitman, 1999), even while lesbian identity may buffer against full-blown body hatred (Owens et al., 2002).

With regard to gender and menstruation, men described menstruation more negatively than women, saying that menstruation debilitated women, dramatically affected their mood (Brooks-Gunn and Ruble, 1986), 
and negatively affected their academic performance (Walker, 1992). Men also expressed uneasiness about women's disclosure of menstruation, even while publicly ascribing women's mood shifts and hostility to menstruation (Christensen and Oei, 1990; Laws, 1992). Such studies raise questions about the role of partner attitudes toward menstruation in (heterosexual) sexual encounters, given this expressed negativity. ${ }^{2}$

While no studies have addressed racial differences in menstrual attitudes, research has explored racial differences among women for body image, selfobjectification and attitudes toward fatness. In US culture, women of color are compared to white women as the 'idealized' standard, engendering women of color to dislike their natural bodies, ethnic features (e.g. 'kinky' hair, almond-shaped eyes), and culturally distinct body practices (Chapkis, 1986; Hill-Collins, 2005). That said, communities of color more often affirm larger bodies, which helps to partially buffer women of color from body shame about weight (Kronenfeld et al., 2010; Miller et al., 2000). Though underdeveloped as a literature, one study addressed race, body image and sexuality, finding that African-American women masturbated far less often, and (contradicting aforementioned studies) had worse body image when compared to white women (Shulman and Horne, 2003).

Some cultural and ethnic differences exist in attitudes toward menstruation, though most cultures describe menstruation negatively. US and Mexican respondents considered menstruating women irritable and moody, and had almost universally negative attitudes toward them, particularly among younger men (Marván et al., 2005, 2008). Similarly, traditional and indigenous Chinese girls described menstruation as a negative event (Yeung et al., 2005). Indian women rated menstruation as more natural and less distressing than US women (Hoerster et al., 2003), indicating that disgust and shame do not universally define women's menstrual experiences.

Despite this sparse literature on connections between women's attitudes about menstruation, body image and sexuality across social identity lines, one recent study directly addressed college women's attitudes toward sex while menstruating (Allen and Goldberg, 2009) (though notably did not collect information about race). This study found that less than half of women engaged in menstrual sex, and that these women were typically younger, in committed relationships, more mature and less disgusted by menstrual sex than others; further, over $80 \%$ of women reported polarized feelings about menstrual sex (e.g. one-third would never do it, while roughly one-third engaged in it regularly and without restrictions) (Allen and Goldberg, 2009).

Other studies have found links between menstruation, sexuality and body image, though women were not directly asked about menstrual sex attitudes. Comfort with menstruation correlated to comfort with sexuality, and engaging in menstrual sex was associated with arousal to romantic activities and less disgust toward one's body (Rempel and Baumgartner, 2003). Women who engaged in menstrual sex also had more partner support than those who avoided menstrual sex (Hensel et al., 2007), again suggesting that 
partner attitudes influence women's menstrual sex attitudes. Also, women who espoused general comfort about menstruation reported more body comfort, sexual assertiveness and sexual experience, but less sexual risk-taking (Schooler et al., 2005).

Across age/racial groups, women have sex far more often while not menstruating than while menstruating (Hensel et al., 2004), though no research has examined possible reasons for this. Some report ovulating women felt more sexual arousal and sexual attractiveness than menstruating women (Jarvis and McCabe, 1991; Röder et al., 2009), though researchers disagree about whether social and cultural reasons (e.g. cultural disgust toward menstruation, negative socialization) drive these findings (Leiblum, 2002), or whether evolutionary and hormonal causes (Mass et al., 2009) are responsible.

Given that the normative climate surrounding menstruation often dictates negative feelings of disgust, shame and embarrassment for menstruating women, and because negativity toward menstruation correlates with poorer body image, I explored the way women interpreted and rationalized engaging in or avoiding sex during menstruation. I also examined whether embracing menstrual sex might link to masturbation attitudes. Further, because women of color face pressures to conform to white norms of body image and sexuality, and because partner choice affects body image attitudes, I explored how social identities related to race and sexuality corresponded with attitudes toward menstrual sex.

\section{METHOD}

This study utilized two waves of qualitative data collection from a sample of 40 women recruited over the span of three years (2005-07). Half the participants (wave 1) were interviewed in a medium-sized Midwestern US city (a 'college town'); the other half (wave 2) in a large metropolitan Southwestern US city. Participants in wave 1 were recruited through local entertainment and arts listings $(N=20)$ distributed free to the local community. Participants in wave 2 were recruited through local entertainment and arts listings $(N=12)$ distributed free to the local community as well as the volunteers section on the local online section of Craigslist $(N=8)$.

Participants were screened only for their gender, racial/ethnic background, sexual identity and age; no other pre-screening questions were asked. A purposive sample was selected: sexual minority women and racial/ethnic minority women were intentionally oversampled; a diverse range of ages was represented (see Tables 69.1 and 69.2). As advertised in the recruitment materials (and approved by the institutional ethics review board), participants were compensated US\$20.00 for participating. All participants consented to have their interviews audiotaped and interviews were fully transcribed using an orthographic style. Identifying data was removed and each participant received a pseudonym to ensure anonymity. Information reported during the 
Table 69.1 Participant demographic information

\begin{tabular}{|c|c|c|c|}
\hline Name & Age & Race & Sexual identity \\
\hline Margaret & 54 & White & Heterosexual \\
\hline Aya & 25 & Chinese-American & Heterosexual \\
\hline Ophelia & 56 & White & Lesbian \\
\hline Susan & 45 & White & Heterosexual \\
\hline Fiona & 24 & White & Bisexual \\
\hline Mitra & 29 & Indian-American & Heterosexual \\
\hline Geena & 51 & White & Heterosexual \\
\hline Courtney & 23 & White & Heterosexual \\
\hline Kate & 25 & White & Heterosexual \\
\hline Leigh & 21 & White & Lesbian \\
\hline Nora & 23 & White & Bisexual \\
\hline Maria & 21 & Mexican-American & Lesbian \\
\hline Priya & 23 & Indian-American & Heterosexual \\
\hline Dorothy & 19 & Chinese-American & Heterosexual \\
\hline Julie & 23 & White & Bisexual \\
\hline Charlene & 44 & Native American & Bisexual \\
\hline Melanie & 21 & White & Heterosexual \\
\hline Pam & 42 & African-American & Heterosexual \\
\hline Anita & 46 & Mexican-American & Heterosexual \\
\hline Lori & 33 & White & Bisexual \\
\hline Esther & 44 & African-American & Heterosexual \\
\hline Janet & 21 & White & Lesbian \\
\hline Brynn & 25 & White & Lesbian \\
\hline Shonda & 44 & African-American & Heterosexual \\
\hline Dawn & 43 & White & Bisexual \\
\hline Bonnie & 51 & White & Heterosexual \\
\hline Marilyn & 54 & White & Heterosexual \\
\hline Lucy & 25 & Mexican-American/Filipina & Bisexual \\
\hline Diana & 50 & White & Lesbian \\
\hline Charlotte & 34 & African-American/Indian-American & Heterosexual \\
\hline Ruth & 46 & White & Heterosexual \\
\hline Jasmine & 37 & Mexican-American & Lesbian \\
\hline Sally & 20 & White & Heterosexual \\
\hline Edie & 19 & White & Heterosexual \\
\hline Jill & 32 & White & Heterosexual \\
\hline Niko & 23 & Asian-American & Heterosexual \\
\hline Ciara & 24 & White & Bisexual \\
\hline Sonja & 24 & White & Heterosexual \\
\hline Emily & 22 & White & Bisexual \\
\hline Carol & 38 & White & Bisexual \\
\hline
\end{tabular}

Note Demographics are self-reported. In the case of sexual identity, their reported behavior, attitudes and attraction do not always align with their self-reported sexual identities

interviews indicated a range of socioeconomic and educational backgrounds, employment histories, and parental and relationship statuses. No significant demographic differences appeared between wave 1 and wave 2 , except that wave 1 participants more often mentioned that they had college or advanced degrees than wave 2 participants. 
Table 69.2 Summary table: Participant demographic information

\begin{tabular}{llc}
\hline Demographic & Percentage & No. of participants \\
\hline Age & & \\
$18-31$ & 52 & 21 \\
$32-45$ & 28 & 11 \\
$46-59$ & 20 & 8 \\
Race & & \\
White & 65 & 26 \\
Women of color & 35 & 14 \\
AfricanAfrican-American & 7.5 & 3 \\
Chicana/Latina & 7.5 & 3 \\
Indian-American & 5 & 2 \\
Asian-American & 7.5 & 3 \\
Native American & 2.5 & 1 \\
Biracial & 5 & 2 \\
Sexual identity & & \\
Heterosexual & 58 & 23 \\
Bisexual & 24 & 10 \\
Lesbian & 18 & 7 \\
Total & 100 & 40 \\
\hline
\end{tabular}

I interviewed participants using a semi-structured interview protocol that lasted for approximately 1.5 to 2 hours, where participants responded to 30 questions about their sexual histories, sexual practices, and feelings and attitudes about sexuality. Several addressed issues relevant to this study. For example, women were asked, 'Many women report that their feelings about their own bodies greatly affect their experience of sex. How do you feel your body image affects your sexual experiences?', with the follow up question: 'How do you feel about having sex while menstruating?' These 30 questions were scripted, but served to open up other conversations and dialogue about related topics, as follow-up questions were free-flowing and conversational. The original questions served as 'sensitizing concepts' that allowed previous research to lay the groundwork for topics and themes to look for (Charmaz, 2006).

Responses were analyzed qualitatively using thematic analysis. This type of analysis was considered the most effective and useful because it allowed for groupings of responses based on women's attitudes and feelings (e.g. acceptance of, neutrality about or disgust toward sex while menstruating, along with accompanying sub-themes). This method of analysis also supported an examination of the intersection between sex and menstruation as well as other components of women's sexual lives (e.g. masturbation). To conduct the analysis, I familiarized myself with the data by reading all of the transcripts thoroughly, and then identified patterns for common interpretations posed by participants. In doing so, I reviewed lines, sentences and paragraphs of the transcripts, looking for patterns in their ways of discussing menstrual sex (Braun and Clarke, 2006). I selected and generated themes through the process of identifying logical links and overlaps between participants. After 
creating these themes, I compared them to previous themes in order to identify similarities, differences and general patterns. This type of thematic analysis relied upon a data-driven inductive approach (Boyatzis, 1998) in which themes were generated prior to interpretation (Boyatzis, 1998). As such, initial themes were identified, codes were applied and then connected back to the themes, and these themes were then corroborated and legitimized, per Fereday and Muir-Cochrane's (2006) method of inductive thematic analysis.

Throughout this process, I relied upon a critical realist framework that contextualized themes and patterns found in the transcripts. While sorting and naming themes required some level of interpretation, I generally did not delve into covert, implicit, or subtextual meanings in the transcript. Women's stories of menstrual sex and masturbation were grouped thematically without undermining their explicit narratives. This study took a contextualist approach as its epistemological framework, as women's narratives were examined discursively for their treatment of gender, sexuality and the body.

\section{RESUlTS}

Overall, 25 women described negative reactions to sex while menstruating, two described neutral reactions and 13 women described positive reactions. Responses did not overlap: no-one identified mixed feelings about sex while menstruating, although women's responses did sometimes overlap between sub-themes (e.g. reporting several negative reactions), and interesting intersections between other sexual practices (masturbation) and identities (race, sexual identity) were noted.

\section{Negative responses to sex during menstruation}

Negative responses cohered around four sub-themes: (1) women's physical discomfort and physical labor; (2) overt partner discomfort; (3) negative self-perception; and (4) emotional labor to manage partner's judgments and feelings. At times, categories overlapped.

Women's physical discomfort and physical labor. Nine women (Bonnie, Aya, Geena, Margaret, Kate, Niko, Sally, Carol and Ruth) mentioned their physical discomfort with menstrual sex, citing logistic problems of cleaning a messy bed, along with the general sentiment that menstruation was difficult to manage. Women took responsibility for the physical labor of cleaning and managing menses, as gendered norms dictate women's management of household cleanliness as 'their job' (Brines, 1994). Bonnie avoided menstrual sex because of cleaning responsibilities: 'It's more my discomfort that my partner's discomfort. I think the messiness of it just gets on things. It's hard to get out of the sheets, the clothes.' Aya also expressed concern about cleaning the mess, linking blood to general dirtiness: 
I wouldn't have sex on my period because I'd rather not dirty the sheets. I'm sure there are guys that don't mind. Even if they wanted to, I don't think that I'd want to. I think blood is dirty. It just seems like such a hassle. Maybe in the shower, but that's the only place that would make sense to me.

Geena provided a particularly vivid example of how physical labor of cleaning deterred her, but also how self-consciousness and emotional labor to manage her partner's judgment fueled disinterest in menstrual sex:

I avoid it, but it's not because I'm not comfortable with it. It's because it makes such a damn mess. You have to get dark-colored towels. It's the pain of cleaning it up and not leaving stains on stuff is why I avoid it, and there's part of me that's always thought that if I'm in the thick of throwing clots, men are not really going to want to do this. They may act all brave and like it's no big deal, but I don't really trust that. It's probably just my own projection, not wanting to deal with the mess.

Overt partner discomfort. Six women (Sally, Pam, Priya, Mitra, Charlene and Sonja) noted that their partners, particularly men, expressed overt discomfort and disgust around sex during menstruation. For example, Sally talked about negative reactions to blood and her boyfriend's aversion: 'My boyfriend didn't like blood, so he would get totally grossed out and we wouldn't have sex for the whole week I was on my period.' Other women, such as Pam, described partners having negative feelings about menses, such as her husband who found it 'gross': 'My husband is uncomfortable about the idea of penetrating me with blood in there. He prefers not to do it. He thinks my period is gross.' Charlene also noted the 'gross' quality of it: 'He thinks it's just messy. And kinda gross.' The concept of 'grossness' appeared frequently in women's talk about menstruation and sex during menstruation, perhaps revealing the strength of their own, and others', disgust reactions toward menstrual sex. The concept of women's bodies as inherently disgusting appeared particularly strongly in these partner aversion stories.

Perhaps testifying to the centrality of partner (dis)affirmation in women's body image and assessment of menstruation, Priya noted that her partner's overt discomfort fed into her own negative feelings about menstruation:

I was with someone and we were going to have sex on my period - this was someone I had been dating for a while, so I was really comfortable - and he was just like, 'I don't want to watch'. I think he was more traumatized than I was and we didn't end up doing it. He was just like, 'I don't want to see blood. I'm going to feel like I'm killing you'. I feel I have so many negative associations with my own period, just having a period on my own is hard so the last thing I need to be doing is doing it with someone else... I've always felt odd because my old roommate told me about how her boyfriend would always go down on her during her period and I just felt like that was something he'd never do. 
Negative self-perception. Fifteen women (Kate, Sonja, Dorothy, Ruth, Jasmine, Edie, Margaret, Aya, Leigh, Priya, Anita, Charlotte, Pam, Courtney and Geena) described negative self-perceptions of body shame and discomfort as key reasons why they avoided menstrual sex. Kate noted that menstruating negatively affected her self-image: 'When I actually have my period I don't usually feel like having sex so much. I feel physically not great, and while I really like to be hugged and to feel physically close, sex feels different. I don't like my body at that time.' Notably, her desire for physical closeness yet no sex suggests that body shame may manifest itself more strongly in sexual contexts compared with physical comfort. Sonja also felt this way, noting that her body shame negatively affected her sexual desire: 'It makes me feel a little bit more uncomfortable about my body. It's kind of grosser. I just feel uncomfortable. I have had sex before on my period, but I always feel gross.' Again, the lack of analysis around where the 'gross' assessments came from (e.g. societal pressures) suggests a link between physical disgust/ aversion and emotions, as women failed to critically examine why they felt 'gross'.

Other women linked menstruation to poor physical well-being, perhaps to manage negative feelings from self and others. Dorothy complained about her menstrual symptoms as a deterrent to sex: 'I'm probably bloated and having cramps and just unhappy already. It just seems like more for the guy, and there's less they can do with your body. It's gross.' Ruth disliked the feel of the blood while having sex, saying: 'It was uncomfortable. The $\mathrm{Ph}$ balance, the blood, had a rougher feel than natural lubrication.'

Some women articulated common cultural assumptions about menstruation as frankly unattractive, using a strong language of disgust and repulsion. Jasmine stated direct aversion to the idea of menstrual sex: 'No, no, no. It just doesn't look pretty. I may be horny, but that's just gross.' Edie echoed this, but unlike most others, reflected on the social location of these personal views: 'My period smells and I don't have a light period. I've been brainwashed somewhere along the lines to think that it's unnatural I guess.' Margaret said, simply: 'It's disgusting.'

Emotional labor to manage partner's judgment. Six women (Mitra, Charlotte, Courtney, Geena, Priya and Ophelia) discussed the emotional labor aspects of managing their partner's judgments about menstrual sex. Mitra worried about her partner's disgust, suggesting that her emotional management of his aversion loomed larger than her own disgust:

My partner isn't fine with it. He's not that into it. I think a lot of men are like that. He's kind of a neat freak so the idea of seeing blood on his penis freaks him out a little bit. It just seems like I would have to put towels down and it just feels like a big thing to worry about - his feelings and this mess.

Charlotte observed that, based on her past experiences, men disliked menstrual sex: 'I've tried it with guys and they didn't like it. They're not used 
to it and they avoid it with me.' Interestingly, Courtney expressly pathologized men who enjoyed menstrual sex as she considered her desire to manage their emotional responses to sex: 'Guys don't think it's hot when women are bleeding. If they do, they're creepy... I try to always shower and stay clean before sex so the guy will enjoy sex.' In summary, women's emotional and physical labor, self-perception and partner perceptions collectively imply that individual, cultural and relational issues all affect women's subjective experiences. These responses point to the centrality of women's internalized body shame narratives as well as both anticipatory and actual responses from partners (particularly men). Women with negative responses often expressed strong, definitive, emotional reactions about women's bodies as 'gross' or repulsive (Fausto-Sterling, 2000). Similarly, even when women did not harbor these views internally, they anticipated that others would feel negatively, and thus internalized a need to 'manage' anti-menstrual attitudes by avoiding sex. This collectively reveals the many layers of shame and negativity women faced when confronting menstrual sex, as tensions between physical and emotional labor, and between partner and self, appeared.

\section{Neutral responses to sex during menstruation}

Two women (Ciara and Emily) described neutral responses to sex while menstruating, noting that it was 'no big deal'. Ciara talked about menstrual sex with her husband in a casual and nonchalant way: 'It wasn't a bad experience. It was kind of weird, but there's nothing bad about it.' Emily also felt this way, saying: 'It's fine. I mean, it makes a lot of laundry [laughs] but I don't think it's a big deal.' These responses reveal that, while many women internalized a strong reaction (negative or positive) to menstrual sex, others did not. While these neutral reactions appeared rarely, their occurrence suggests that some women may resist negative characterizations of their body simply by constructing menstruation as 'no big deal'.

\section{Positive responses to sex during menstruation}

Positive responses to sex while menstruating were categorized into two themes: (1) Physical and emotional pleasure from sex while menstruating; and (2) Rebellion against anti-menstrual attitudes.

Physical and emotional pleasure. Ten women (Susan, Janet, Dawn, Diana, Maria, Lucy, Marilyn, Julie, Esther and Brynn) described menstrual sex as physically and/or emotionally pleasurable. Susan talked about enjoying sex while menstruating despite its messiness: 'I accept it. I'll say, "If you don't care about it, I don't care about it." Let's put down a towel. The sex on my period probably feels the best of almost any time of the month, so it doesn't bother me.' Janet had overwhelmingly positive feelings, noting that menstrual sex conveyed love and acceptance from her partner: 
The first time it happened it was like, 'Oh my God', a totally different experience. It was better than anything I've ever known. In your mind you're like, 'That's a bloody mess!' In my heart it was like, damn, she doesn't really care, she really loves me, 'cause she doesn't care if I'm bleeding or not, and I don't care if she is.

This suggests that sex while menstruating can represent a combination of physical pleasure and emotional pleasure, perhaps because of the coupled subversion of anti-menstrual attitudes. In other words, satisfaction with menstrual sex may reflect feelings of acceptance, validation, warmth and love, all of which typically fall under emotional satisfaction from sex. This supports other research that has shown that women often conflate physical and emotional satisfaction when reporting on general sexual satisfaction (McClelland, 2010).

Women also described having intense orgasms during sex while menstruating, such as Dawn: 'I have no problem with sex while menstruating. I actually have some of the most intense orgasms right at the beginning of my period and right at the end of my period. Of course I'm always happy I'm not pregnant!' Diana also embraced the pleasurable aspects of sex while menstruating, saying: 'I'm perfectly fine with it if it's not heavy... It can be really arousing.' This differed from earlier negative responses in which women identified feeling 'horny' yet avoided sex because of negative social penalties (e.g. Jasmine).

Some women also described increased bodily responsiveness while menstruating, noting that physical changes felt erotic. These women situated their desire for menstrual sex as bodily rather than about partners, and described sensual details about the encounters. Marilyn described her body as 'more moist, just so much more moist, so it's pleasurable'. Julie also felt more sexual desire while menstruating: 'It feels really good. It's a time when I often desire it, particularly with my partners that are men, and it feels really good to them too. It's really warm and good. It's messy and I like that. I think it's fun.' Esther similarly noted: 'Right before my period, I'm at a peak when I really feel a strong desire for sex. My cramps are usually so bad the first couple of days, so there's no way I can even think about it, but after that point, it really doesn't bother me. It's fun.' Brynn described her body's physical changes as arousing, and admitted to seeking out sex while menstruating: 'I would have to say that sex while menstruating is awkwardly a bit more pleasurable because my senses are a little more heightened, my feelings are more on edge. It's more pleasurable. It's just a totally different experience.'

Rebellion against anti-menstrual attitudes. Finally, three women (Nora, Fiona and Lori), notably all feminist-identified, constructed menstrual sex as a way to rebel against anti-menstrual attitudes by embracing their natural bodies and affirming their womanhood. Nora discussed her progression from reluctance to fully embracing menstrual sex as a wonderfully messy occurrence: 
At first I was really kind of amazed, held back by it. I remember learning very early that you could have sex on your period, and I was blown away by that and kind of grossed out at the same time, but then after I started having sex on my own, I enjoyed it. Usually it can help with my cramps... [My first boyfriend] allowed me to finger- paint on his chest with my menstrual blood. I really enjoyed that as a great expression. This one guy recently asked me to put a towel down and I was like, 'Whatever.' I've definitely made total messes and there's some satisfaction in that to be honest. I've definitely messed up white towels and white comforters and totally made things messy, and for whatever reason I don't have any regret or shame about that. I'm just like, 'Oh, that's nice.'

Fiona described menstrual sex as rejecting negative stereotypes about women's bodies: 'I don't like to think about my body as smelly or dirty. Having sex on my period is a way to prove that my boyfriend doesn't think of me this way either.' Lori believed that menstrual sex affirmed her body image and created a shared rebellion between her and her partner: 'Most of the time girls are told that their bodies are gross and disgusting, and I always feel like having sex while I'm bleeding is a way to go against that, like my boyfriend and I are staging a private little rebellion. I feel like an animal or something, kind of like when I gave birth and I felt just this life force coming out of me.'

\section{Connections to masturbation experiences}

To expand the discussion of menstrual sex attitudes into a larger conversation about body shame, attitudes about masturbation were also examined. Interestingly, positive attitudes about menstrual sex also closely aligned with positive attitudes toward masturbation, as all but two of the 13 women describing menstrual sex positively had positive experiences with masturbation as well. Similar findings did not appear for those with negative attitudes toward menstrual sex, as their masturbation attitudes were more inconsistent. Specifically, of the 25 women with negative feelings toward menstrual sex, eight did not enjoy masturbating. That positive feelings toward menstrual sex appeared often in tandem with positive attitudes toward masturbation suggests that women who affirmed menstruation and experienced less body shame about menstrual sex may also have felt more positively about their bodies in general.

To highlight some positive responses, consider Dawn's views about enjoyment of masturbation and her framing of this as body affirmation: 'I masturbate about once per week. It makes me feel in control, like I have a deeper connection with my body.' Emily also happily expressed shameless enjoyment of masturbation along with positive experiences with menstrual sex:

I love it! I have been masturbating for about as long as I can remember. In middle school, I must have tripled my parent's water bill just by playing around in the shower [laughs]. I masturbate daily, unless I get interrupted at it or 
something. I'm very unapologetic about masturbation. I'm like, 'Can a girl masturbate in peace please?'

Lucy also noted the importance of shared communities around sexual openness, as talking about masturbation (something women often avoid, see Jones, 2002) helped her confidence and positivity toward masturbation:

I have had really good experiences masturbating and I think it's taught me what I like, and I've been able to have better sex because of it. I masturbate probably three or four times a week.. I'm kind of a hippie, so all of my friends that are hippies are also very, very open with masturbation too.

In contrast, negativity toward menstrual sex often aligned with negativity toward masturbation, though this was much more inconsistent. Charlotte described self-doubt and anxiety about masturbation:

I don't mean to sound like a prude, but I've never done that. It just seems weird that everyone's like, 'It's normal. You can get a toy or get a guy to get a toy.' I tried once and it felt weird, just so awkward. I felt like, 'What are you doing? You're a weirdo.'... I've talked to people who say it's a piece of cake, but I just have never had the pleasure to experience it like that.

Interestingly, Charlotte situated her lack of interest in masturbation as clearly freakish or abnormal, which did not appear in women's discussion of menstrual sex; perhaps women more clearly normalized masturbation as 'something everyone does', while menstrual sex may still lack a social comparison dimension. Nonetheless, clear similarities between liking masturbation and liking menstrual sex suggest that more body affirmation and less body shame led to positive feelings about these dimensions of sexuality.

Intersections of identities and menstrual sex experiences. In addition to connections between masturbation and menstrual sex attitudes, social identities also factored centrally in women's accounts of sex while menstruating. Race and sexual identity differences appeared, as a mere three out of 13 positive responses toward menstrual sex were provided by women of color, indicating that white women in this sample felt more positively toward menstrual sex than did women of color. Notably, women who embraced positive feelings about menstrual sex were more often white and bisexual or lesbian. Only three of the heterosexual-identified respondents described menstrual sex as positive; the remaining 22 had negative feelings. Both women who described neutral feelings identified as white and bisexual. More women of color and heterosexual women (including heterosexual women of color specifically) described sex while menstruating as a negative experience. These results collectively raise questions about the relationship between social identities and menstrual sex attitudes, discussed further in the next section. 


\section{Discussion}

Collectively, these results raise questions about how women learn to embrace sex while menstruating, who they embrace it with and why they embrace it. Equally interesting questions are raised about how, why and with whom some women reject menstrual sex. Though I initially did not prioritize examining the relationship between social identities and menstrual sex attitudes, these findings suggest that both race and sexual identity may relate to women's attitudes about sex while menstruating. Those describing positive experiences with menstrual sex overwhelmingly included white, lesbian or bisexual-identified women, indicating that women of color and heterosexual women far more often reported negative experiences with sex while menstruating. Additionally, those espousing positive experiences with menstrual sex more often described positive experiences with masturbation compared to those with negative menstrual sex attitudes. Further, intersections between race and sexuality were noted, as more women of color identified as heterosexual, while more white women identified as bisexual or lesbian, indicating that many of the results speak to the experiences of heterosexual women of color and bisexual/lesbian white women.

Such results tap into existing research on racial differences in body image and sexual practices, as white women receive more cultural and social validation for their bodies (albeit within narrowly prescribed limits of thinness and beauty), and they may benefit from a culture that values and celebrates white bodies (Molloy and Herzberger, 1998; Patton, 2010; Stephens and Phillips, 2005). There are many possible reasons why white women more often expressed positive feelings toward menstrual sex and masturbation. The oversexualization of women of color, particularly in pop media (Sengupta, 2006), combined with the pervasive influence of whiteness as a primary criterion of beauty (Hill-Collins, 2005), may influence women's relationship to menstruation and other body norms (e.g. shaving, dress, hairstyles, etc.). Within communities of color, a taboo against sex while menstruating may exist more prominently than it does for whites, likely because menstrual taboos exist more prominently within communities of color (Bobel, 2010). As Bobel argued in a recent interview, 'Menstrual activism is risky business for all, and especially for women of color, whose bodies have been denigrated throughout history. Taking on the menstrual taboo can make others see you as nasty, gross, improper... and if you're already struggling to be accepted and taken seriously, then why go "there"? (Nack, 2010).

One could compellingly argue that partner aversion also played a major role in these findings, as most women who discussed partner aversion were women of color (eight out of 12). Or, negative menstrual sex attitudes may stem from both women and their partners engaging in a cyclical dance of aversion. Clearly, women battle not only their own internalized body shame about menstruation and masturbation, but also their partner's 
communication of this body shame as well (Bobel, 2010); women of color may face steeper battles in affirming both masturbation and menstruation. These findings are particularly interesting in light of studies that show African-American women reporting lower body dissatisfaction about weight (Kronenfeld et al., 2010; Miller et al., 2000; Sabik et al., 2010), indicating a contrast between attitudes about different body 'taboos'. These discrepancies also suggest that conceptualizations of body image and body shame may have overvalued emphasis on weight and thinness and undervalued other social norms about bodies (Davis et al., 2010). Nonetheless, this study suggests that women of color and white women differently experienced sex during menstruation, warranting further research about why women of color are not more buffered against negative menstrual attitudes.

Additionally, the sexual identity findings point to some troubling aspects of heterosexuality and the possibly liberatory aspects of lesbianism and bisexuality, as lesbian and bisexual women overwhelmingly embraced menstrual sex compared to heterosexual women. Notably, negative feelings about menstrual sex did not exclusively correlate with the choice of male partners instead of female partners, as bisexual women having sex with men overwhelmingly had positive experiences with sex while menstruating - and mostly they spoke of sex with male partners. Rather, heterosexual identity seemed more related to shame about menstrual sex and negative experiences with masturbation. Perhaps queer identity makes women less likely to seek out the male gaze (Walker, 1995), or perhaps queer women have considered alternatives to male partnerships and thus have chosen different types of men. For example, one study found that queer women more often viewed their sexual identity as involving a conscious, effortful process than did heterosexual women (Konik and Stewart, 2004), implying that bisexual women may choose men consciously and less as a social mandate. As such, if bisexual and lesbian identity link with positive and affirming self-attitudes, future research could interrogate the strengths and limitations of this finding, particularly as they relate to intersections between race and sexuality. For example, perhaps heterosexual women of color might use negative menstrual sex attitudes to deny men sexual access to their bodies, indicating a subversion of the 'sexually available' woman of color cultural narrative (Hurtado, 1989).

Looking more broadly, these findings suggest that women may resist body shame by choosing affirmative partners. Janet's description of menstrual sex as loving and affirming and Lori's conceptualization of her mutual private rebellion suggest this possibility. Similarly, those managing partner aversion show that partner choice can negatively impact women's menstrual sex attitudes. Heterosexual women often prioritize their partners' pleasure over their own when assessing sexual satisfaction (Nicolson and Burr, 2003; Traeen and Skogerbo, 2009), so avoiding menstrual sex may also satisfy their partners' needs or wants if their partners dislike menstrual sex. Women's attitudes may change from partner to partner as well, so longitudinal data could 
prove interesting. Clearly, the gender of women's partners matters, as women's female partners more often embraced menstrual sex than did women's male partners. That said, bisexual women often selected male partners who appeared to eroticize menstruation. More research about mutually affirming body processes in lesbian partnerships could be useful, particularly since lesbian relationships were found to be more satisfying, egalitarian, empathic and better at conflict resolution compared to heterosexual relationships (Ussher and Perz, 2008), as would research about which men support women's body affirmations.

This study adds to existing literatures on sexuality, menstruation and masturbation in several ways. First, few studies have directly examined women's qualitative feelings about menstrual sex (Allen and Goldberg, 2009, is the notable exception, though they utilized a heterosexual college sample and did not interrogate race). Research studies have typically neglected material about women's thought processes, feelings, emotions and rationalizations, preferring instead to study frequencies and behavior. Qualitative methods allow a deeper, more textured, interrogation of these aspects of women's lives. Second, while this study nuances women's overwhelmingly negative attitudes toward menstrual sex - layering together their own disgust, emotional labor and partner aversion - many women successfully subverted anti-menstruation attitudes by seeing menstruation as positive and erotic. This study offers qualitative insight about the frameworks within which women rebel against social norms that require them to keep menstruation hidden and secretive. Women's body affirmations occur often, and in spite of, negative normative social pressures. Whether this represents feminist consciousness remains an open question, though the groundwork for feminist beliefs appeared in several responses (e.g. Edie's suggestion that she had been 'brainwashed'); certainly, feminist consciousness has predicted better body image and comfort with bodily processes (Murnen and Smolak, 2009; Peterson et al., 2006), and all three 'rebellion' comments in this study were made by feminist women.

Additionally, this study helps connect the dots between attitudes toward menstrual sex and other aspects of body affirmation such as enjoyment of masturbation; women may subvert norms of body shame in multiple spheres of their lives. Though limited in scope and detail, a connection between menstrual sex and masturbation appeared. Future research could determine what other social attitudes might attach to these positive or affirming views (e.g. refusing to fake orgasms, rejecting shaving norms, embracing natural or home births, rejecting psychotropic medications, affirming fatness, and so on). These connections may expand ideas about bodies and sexualities. Women who feel less shame about menstruation may have more comfort with sexuality in general (Schooler et al., 2005), while masturbation experiences may fuel better body image (thus addressing a notable gap in existing literatures - see Coleman, 2002). Women in this study could, and often did, resist negative 
characterizations of their bodies as disgusting, abhorrent, dirty and shameful by instead creating new narratives of affirmation and support. More research is needed to determine which women better resist cultural constructions of women's bodies as disgusting, and how they go about creating these alternative narratives. Knowing about the relationship between social identities, body image and narratives of shame can nuance our understanding of how different women are differently affected by these social norms. Further, it can support relevant social, psychological and public policies about body image (e.g. eating disorder treatments, educational interventions, psychotherapy treatments, medical interventions and body activism).

In light of this, perhaps other social identities may also contribute to attitudes toward menstrual sex, as socioeconomic class, geographic location and educational background likely affect women's experiences with their bodies. Clearly, educational experiences matter, because women's studies classes foster greater feminist consciousness among female students (Henderson-King and Stewart, 1999; Stake and Rose, 1994), and feminist consciousness is directly associated with better body image (Murnen and Smolak, 2009; Peterson et al., 2006). Also, social class affects women's perceptions of their bodies (Fahs and Delgado, in press; McLaren and Kuh, 2004), indicating it likely also affects menstrual attitudes. Similarly, life experiences surely affect women's relationships with their bodies, as sexual assault (Campbell and Soeken, 1999), parental divorce (Billingham and Abrahams, 1998), and pregnancy and post-pregnancy (Clark et al., 2009) predict poorer body image. Future research could examine whether sexual assault, abortion, divorce, pregnancy and post-pregnancy affect women's ideas about menstrual sex.

Several limitations are noted. First, though a framework for some patterns was established - including patterns surrounding race, sexual identity and masturbation - quantitative research could differently address these connections, perhaps situating women along a continuum for each dimension. Though this study examined race and included many women of color from diverse backgrounds, future qualitative work could more directly discuss women's ideas about how race and sexual identity relate to their sexuality, body image, and ideas about menstrual sex. Also, this sample may have over-selected for those more interested in sexuality who had less shame about sexuality. Notably, women sometimes avoid sex research as a privacy invasion (Boynton, 2003), and may narrate their sexual experiences in relation to the wishes and needs of their (male) partners (McClelland, 2010).

In sum, while this study suggests that most women felt negatively toward menstrual sex - thus confirming common cultural assumptions about menstruation as dirty and shameful - many women resisted such characterizations by instead eroticizing menstruation and, in some cases, affirming their bodies in other ways (e.g. masturbation). Women's partnerships with women and also (some) men may serve as important sites for such resistance. Further, 
the finding that heterosexual identity more than heterosexual activity seemed related to negative attitudes toward menstrual sex presents a curious interpretation of gender, sexuality and identity. Much work remains in facilitating women's acceptance and embracing of their bodies, particularly around common cultural taboos such as menstruation. Research must continue to examine - both qualitatively and quantitatively - the interplay between pleasure, sexuality, emotions, identities and social justice. ${ }^{3}$

\section{Notes}

1. "Sex during Menstruation: Race, Sexual Identity, and Women's Qualitative Accounts of Pleasure and Disgust" by Breanne Fahs was first published in 2011 in Feminism \& Psychology 21 (2): 155-78. Reprinted with permission. No further reproduction or distribution of the material is allowed without permission from the publisher.

2. In response to men's negative attitudes, Gloria Steinem (1986) has sarcastically suggested that, if men could menstruate, congress would subsidize menstrual pads, men would brag about their flow, and the military would require menstruation to enlist.

3. Special thanks to Jennifer Bertagni, Kathleen Courter, Judith Sipes, and Eric Swank for their help in preparing this manuscript.

\section{REFERENCES}

Allen KR and Goldberg AE (2009) Sexual activity during menstruation: A qualitative study. Journal of Sex Research 6(1): 1-11.

Amann-Gainotti M (1994) Adolescent girls' internal body image. International Journal of Adolescent Medicine and Health 7(1): 73-86.

Aretxaga B (1995) Symbolic and over determination and gender in Northern Ireland ethnic violence. Ethos 23(2): 123-148.

Berg DH and Coutts LB (1994) The extended curse: Being a woman every day. Health Care for Women International 15(1): 11-22.

Billingham R and Abrahams T (1998) Parental divorce, body dissatisfaction, and physical attractiveness ratings of self and others among college women. College Student Journal 32(1): 148-1052.

Bobel C (2006) 'Our revolution has style': Contemporary menstrual product activists 'doing feminism' in the third wave. Sex Roles 54(5-6): 331-345.

Bobel C (2008) From convenience to hazard: A short story of the emergence of the menstrual activism movement, 1971-1992. Health Care for Women International 29(7): 738-754.

Bobel C (2010) New Blood: Third Wave Feminism and the Politics of Menstruation. Camden, NJ: Rutgers University Press.

Boyatzis R (1998) Transforming Qualitative Information: Thematic Analysis and Code Development. Thousand Oaks, CA: Sage.

Boynton PM (2003) 'I'm just a girl who can't say no'? Women, consent, and sex research. Journal of Sex e Marital Therapy 29(1): 23-32.

Brain JL (1988) Male menstruation in history and anthropology. The Journal of Psychohistory 15(3): 311-323. 
Braun V and Clarke V (2006) Using thematic analysis in psychology. Qualitative Research in Psychology 3(1): 77-101.

Briefel A (2005) Monster pains: Masochism, menstruation, and identification in the horror film. Film Quarterly 58(3): 17-27.

Brines J (1994) Economic dependency, gender, and the division of labor at home. The American Journal of Sociology 100(3): 652-688.

Brooks-Gunn J and Ruble DN (1986) Men's and women's attitudes and beliefs about the menstrual cycle. Sex Roles 14(5-6): 287-299.

Burrows A and Johnson S (2005) Girls' experiences of menarche and menstruation. Journal of Reproductive and Infant Psychology 23(3): 235-249.

Campbell JC and Soeken KL (1999) Forced sex and intimate partner violence: Effects on women's risk and women's health. Violence Against Women 5(9): 1017-1035.

Charmaz C (2006) Constructing Grounded Theory. London: Sage.

Chapkis W (1986) Beauty Secrets: Women and the Politics of Appearance. Boston, MA: South End Press.

Chrisler JC, Rose JG, Dutch SE, Sklarsky KG and Grant MC (2006) The PMS illusion: Social cognition maintains social construction. Sex Roles 54(5-6): 371-376.

Christensen AP and Oei TP (1990) Men's perception of premenstrual changes on the premenstrual assessment form. Psychological Reports 66(2): 615-619.

Clark A, Skouteris H, Wertheim EH, Paxton SJ and Milgrom J (2009) My baby body: A qualitative insight into women's body-related experiences and mood during pregnancy and the postpartum. Journal of Reproductive and Infant Psychology 27(4): 330-345.

Coleman E (2002) Masturbation as a means of achieving sexual health. Journal of Psychology and Human Sexuality 14(2-3): 5-16.

Cosgrove L and Caplan PJ (2004) Bias in Psychiatric Diagnosis: A Project of the Association for Women in Psychology. Lanham, MD: Jason Aronson Press.

Davis DS, Sbrocco T, Odoms-Young A and Smith DM (2010) Attractiveness in African American and Caucasian women: Is beauty in the eyes of the observer? Eating Behaviors 11(1): 25-32.

Delaney J, Lupton MJ and Toth E (1988) The Curse: A Cultural History $f$ Menstruation. Chicago: University of Illinois Press.

Endicott J, Amsterdam J, Eriksson E, Frank E, Freeman E, Hirschfeld R, Ling F, Parry B, Pearlstein T, Rosenbaum J, Rubinow D, Schmidt P, Severino S, Steiner M, Stewart DE and Thys-Jacobs S (1999) Is premenstrual dysphoric disorder a distinct clinical entity? Journal of Women's Health and Gender-Based Medicine 8(5): 663-679.

Erchull MJ, Chrisler JC, Gorman JA and Johnston-Robledo I (2002) Education and advertising: A content analysis of commercially produced booklets about menstruation. Journal of Early Adolescence 22(4): 455-474.

Fahs B and Delgado D (in press) The specter of excess: Race, class, and gender in women's body hair narratives. In: Bobel C and Kwan S (eds) Embodied resistance: Breaking the rules, challenging the norms. Nashville: Vanderbilt University Press.

Fausto-Sterling A (2000) Sexing the Body: Gender Politics and the Construction of Sexuality. New York: Basic Books.

Fereday J and Muir-Cochrane E (2006) Demonstrating rigor using thematic analysis: A hybrid approach of inductive and deductive coding and theme development. International Journal of Qualitative Methods 5(1): 1-11.

Havens BB and Swenson I (1989) A content analysis of educational media about menstruation. Adolescence 24(6): 901-907. 
Henderson-King D and Stewart AJ (1999) Educational experiences and shifts in group consciousness: Studying women. Personality and Social Psychology Bulletin 25(3): 390-399.

Hensel DJ, Fortenberry JD and Orr DP (2007) Situational and relational factors associated with coitus during vaginal bleeding among adolescent women. Journal of Sex Research 44(3): 269-277.

Hensel DJ, Fortenberry JD, Harezlak J, Anderson JG and Orr DP (2004) A daily diary analysis of vaginal bleeding and coitus among adolescent women. Journal of Adolescent Health 34(5): 391-394.

Hill-Collins P (2005) Black Sexual Politics: African Americans, Gender, and the New Racism. New York: Routledge.

Hoerster KD, Chrisler JC and Rose JG (2003) Attitudes toward and experience with menstruation in the US and India. Women and Health 38(3): 77-95.

Hurtado A (1989) Relating to privilege: Seduction and rejection in the subordination of white women and women of color. Signs 14(4): 833-855.

Jarvis TJ and McCabe MP (1991) Women's experience of the menstrual cycle. Journal of Psychosomatic Research 35(6): 651-660.

Johnston-Robledo I, Barnack J and Wares S (2006) 'Kiss your period good-bye': Menstrual suppression in the popular press. Sex Roles 54(5-6): 353-360.

Johnston-Robledo I, Ball M, Lauta K and Zekoll A (2003) To bleed or not to bleed: Young women's attitudes toward menstrual suppression. Women \& Health 38(3): $59-75$.

Johnston-Robledo I, Sheffield K, Voigt J and Wilcox-Constantine J (2007) Reproductive shame: Self-objectification and young women's attitudes toward their reproductive functioning. Women and Health 46(1): 25-39.

Jones R (2002) 'That's very rude, I shouldn't be telling you that': Older women talking about sex. Narrative Inquiry 12(1): 121-143.

Kerkham P (2003) 'Menstruation - The gap in the text? Psychoanalytic Psychotherapy 17(4): 279-299.

Kissling EA (2002) On the rag on screen: Menarche in film and television. Sex Roles 46(1-2): 5-12.

Kissling EA (2006) Capitalizing on the curse: The business of menstruation. Boulder, CO: Lynne Rienner.

Kleinplatz P (2001) New directions in sex therapy: Innovations and alternatives. New York: Routledge.

Koekse R (1983) Lifting the curse of menstruation: Toward a feminist perspective on the menstrual cycle. Pittsburg, PA: Haworth Press.

Konik J and Stewart AJ (2004) Sexual identity development in the context of compulsory heterosexuality. Journal of Personality 72(4): 815-844.

Kronenfeld LW, Reba-Harrelson L, Von Holle A, Reyes ML and Bulik CM (2010) Ethnic and racial differences in body size perception and satisfaction. Body Image $7(2): 131-136$.

Laws S (1992) 'It's just the monthlies, she'll get over it': Menstrual problems and men's attitudes. Journal of Reproductive and Infant Psychology 10(2): 117-128.

Leiblum SR (2002) Reconsidering gender differences in sexual desire: An update. Sexual and Relationship Therapy 17(1): 57-68.

Mansfield PK and Stubbs ML (2007) The menstrual cycle: Feminist research from the Society for Menstrual Cycle Research. Women \& Health 46(1): 1-5. 
Martin E (2001) The woman in the body: A cultural analysis of reproduction. Boston, MA: Beacon Press.

Marva' n ML, Corte' s-Iniestra S and Gonza' lez R (2005) Beliefs about and attitudes toward menstruation among young and middle-aged Mexicans. Sex Roles 53(3-4): 273-279.

Marva' n MI, Islas M, Vela L, Chrisler JC and Warren EA (2008) Stereotypes of women in different stages of their reproductive life: Data from Mexico and the United States. Health Care for Women International 29(7): 673-687.

Mass R, Ho“ lldorfer M, Moll B, Bauer R and Wolf K (2009) Why we haven't died out yet: Changes in women's mimic reactions to visual erotic stimuli during their menstrual cycles. Hormones and Behavior 55(2): 267-271.

McClelland SI (2010) Intimate justice: A critical analysis of sexual satisfaction. Social and Personality Psychology Compass 4(9): 663-680.

McKinley NM, Lyon LA, McKinley AF, Nita M and Lyon LA (2008) Menopausal attitudes, objectified body consciousness, aging anxiety, and body esteem: European American women's body experiences in midlife. Body Images 5(4): 375-380.

McLaren L and Kuh D (2004) Women's body dissatisfaction, social class, and social mobility. Social Science and Medicine 58(9): 1575-1584.

Miller KJ, Gleaves DH, Hirsch TG, Green BA, Snow AC and Corbett CC (2000) Comparisons of body image dimensions by race/ethnicity and gender in a university population. International Journal of Eating Disorders 27(3): 310-316.

Molloy BL and Herzberger SD (1998) Body image and self-esteem: A comparison of African-American and Caucasian women. Sex Roles 38(7-8): 631-643.

Mottola G (2007) Superbad. USA: Columbia Pictures.

Murnen SK and Smolak L (2009) Are feminist women protected from body image problems? A meta-analytic review of relevant research. Sex Roles 60(3-4): 186-197.

Nack A (2010) Bedside manners: New blood, and a new view of menstrual activism. Girl w/ Pen: Bridging Feminist Research and Popular Reality. Available at: girlwpen.com/. ? p $1 / 41902$.

Nicolson P (1995) The menstrual cycle, science and femininity: Assumptions underlying menstrual cycle research. Social Science and Medicine 41(6): 779-784.

Nicolson P and Burr J (2003) What is 'normal' about women's (hetero)sexual desire and orgasm? A report of an in-depth interview study. Social Science \& Medicine 57(9): 1735-1745.

Nobre PJ and Pinto-Gouveia J (2008) Cognitive and emotional predictors of female sexual dysfunctions: Preliminary findings. Journal of Sex \& Marital Therapy 34(4): $325-342$.

Offman A and Kleinplatz PJ (2004) Does PMDD belong in the DSM? Challenging the medicalization of women's bodies. Canadian Journal of Human Sexuality 13(1): 17-27.

Owens LK, Hughes TL and Owens-Nicholson D (2002) The effects of sexual orientation on body image and attitudes about eating and weight. Journal of Lesbian Studies 7(1): 15-33.

Patton TO (2010) Hey girl, am I more than my hair? African American women and their struggles with beauty, body image, and hair. In: Moore LJ and Kosut M (eds) The Body Reader: Essential Social and Cultural Readings. New York: New York University Press, 349-366 
Peterson RD, Tantleff-Dunn S and Bedwell JS (2006) The effects of exposure to feminist ideology on women's body image. Body Image 3(3): 237-246.

Pitman GE (1999) Body image, compulsory heterosexuality, and internalized homophobia. Journal of Lesbian Studies 3(4): 129-140.

Plante R (2006) Sexualities in Context: A Social Perspective. Boulder, CO: Westview Press.

Read S (2008) Thy righteousness is but a menstrual clout: Sanitary practices and prejudice in early modern England. Early Modern Women: An Interdisciplinary Journal 3: $1-25$.

Rembeck GI, Moller MM and Gunnarsson RK (2006) Attitudes and feelings towards menstruation and womanhood in girls at menarche. Acta Paediatrica 95(6): 707-714.

Rempel JK and Baumgartner B (2003) The relationship between attitudes toward menstruation and sexual attitudes, desires, and behavior in women. Archives of Sexual Behavior 32(2): 155-163.

Roberts TA and Goldenberg JL (2007) Wrestling with nature: An existential perspective on the body and gender in self-conscious emotions. In: Tracy JL, Robins RW and Tangney JP (eds) The Self-conscious Emotions: Theory and Research. New York: Guilford Press, 389-406.

Roberts TA and Waters PL (2004) Self-objectification and that 'not so fresh feeling': Feminist therapeutic interventions for healthy female embodiment. Women and Therapy 27(3-4): 5-21.

Röder S, Brewer G and Fink B (2009) Menstrual cycle shifts in women's self-perception and motivation: A daily report method. Personality and Individual Differences 47(6): 616-619.

Rose JG, Chrisler JC and Couture S (2008) Young women's attitudes toward continuous use of oral contraceptives: The effect of priming positive attitudes toward menstruation on women's willingness to suppress menstruation. Health Care for Women International 29(7): 688-701.

Sabik NJ, Cole ER and Ward ML (2010) Are all minority women equally buffered from both negative body image? Intra-ethnic moderators of the buffering hypothesis. Psychology of Women Quarterly 34(2): 139-151.

Schooler D, Ward LM, Merriwether A and Caruthers AS (2005) Cycles of shame: Menstrual shame, body shame, and sexual decision-making. Journal of Sex Research 42(4): 324-334.

Sengupta R (2006) Reading representations of black, east Asian, and white women in magazines for adolescent girls. Sex Roles 54(11-12): 799-808.

Shulman JL and Horne SG (2003) The use of self-pleasure: Masturbation and body image among African Americans and women. Psychology of Women Quarterly 27(3): $262-269$.

Stake JE and Rose S (1994) The long-term impact of women's studies on students' personal lives and political activism. Psychology of Women Quarterly 18(3): $403-412$.

Steinem G (1986) Outrageous Acts and Everyday Rebellions. New York: Holt.

Stephens DP and Phillips L (2005) Integrating Black feminist though into conceptual frameworks of African American adolescent women's sexual scripting processes. Sexualities, Evolution, and Gender 7(1): 37-55.

Stubbs MI and Costos D (2004) Negative attitudes toward menstruation: Implications for disconnection within girls and between women. Women and Therapy 27(3-4): 37-54. 
Tiefer L (2001) Sex is not a Natural Act and Other Essays. Boulder, CO: Westview Press.

Tiggemann M and Lewis C (2004) Attitudes toward women's body hair: Relationship with disgust sensitivity. Psychology of Women Quarterly 28(4): 381-387.

Traeen B and Skogerbo A (2009) Sex as an obligation and interpersonal communication among Norwegian heterosexual couples. Scandinavian Journal of Psychology 50(3): 221-229.

Ussher JM and Perz J (2008) Empathy, egalitarianism, and emotion work in the relational negotiation of PMS: The experience of women in lesbian relationships. Feminism er Psychology 18(1): 87-111.

Walker A (1992) Men's and women's beliefs about the influence of the menstrual cycle on academic performance: A preliminary study. Journal of Applied Social Psychology 22(11): 896-909.

Walker L (1995) More than just skin-deep: Fem(me)ninety and the subversion of identity. Gender, Place, \& Culture 2(1): 71-76.

Yeung DYL, Tang CSK and Lee A (2005) Psychosocial and cultural factors influencing expectations of menarche: A study on Chinese premenarchal teenage girls. Journal of Adolescent Research 2(1): 118-135.

Zepeda G and Eugenia B (1999) Erotic sexuality in lesbian and heterosexual females. Archivos Hispanoamericanos de Sexologia 5(1): 93-115.

Open Access This chapter is licensed under the terms of the Creative Commons Attribution 4.0 International License (http://creativecommons.org/licenses/ by/4.0/), which permits use, sharing, adaptation, distribution and reproduction in any medium or format, as long as you give appropriate credit to the original author(s) and the source, provide a link to the Creative Commons license and indicate if changes were made.

The images or other third party material in this chapter are included in the chapter's Creative Commons license, unless indicated otherwise in a credit line to the material. If material is not included in the chapter's Creative Commons license and your intended use is not permitted by statutory regulation or exceeds the permitted use, you will need to obtain permission directly from the copyright holder.

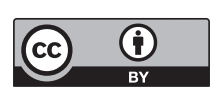

